\title{
Molecular mechanisms mediating stiffening in the mechanically adaptable connective tissues of sea cucumbers
}

Marie Bonneel

University of Mons https://orcid.org/0000-0002-3360-2783

Elise Hennebert

University of Mons

Sesilja Aranko

Aalto University

Dong Soo Hwang

Pohang University of Science and Technology (POSTECH) https://orcid.org/0000-0002-2487-2255

Mathilde Lefevre

University of Mons

Valentine Pommier

University of Mons

\section{Ruddy Wattiez}

University of Mons

Jérôme Delroisse

University of Mons

Patrick Flammang ( $\nabla$ patrick.flammang@umons.ac.be )

University of Mons https://orcid.org/0000-0001-9938-1154

\section{Article}

Keywords: sea cucumbers, connective tissues, mutable collagenous tissues

Posted Date: May 13th, 2021

DOI: https://doi.org/10.21203/rs.3.rs-479625/v1

License: (c) (i) This work is licensed under a Creative Commons Attribution 4.0 International License. Read Full License

Version of Record: A version of this preprint was published at Matrix Biology on February 1st, 2022. See the published version at https://doi.org/10.1016/j.matbio.2022.02.006. 



\title{
Molecular mechanisms mediating stiffening in the mechanically adaptable connective tissues of sea cucumbers
}

\author{
Marie Bonneel $^{1 \dagger}$, Elise Hennebert ${ }^{2 \dagger}$, A. Sesilja Aranko ${ }^{3}$, Dong Soo Hwang ${ }^{4}$, Mathilde
} Lefevre $^{2,5}$, Valentine Pommier ${ }^{1}$, Ruddy Wattiez ${ }^{6}$, Jérôme Delroisse ${ }^{1}$ and Patrick Flammang ${ }^{1 *}$

${ }^{1}$ Biology of Marine Organisms and Biomimetics Unit, Research Institute for Biosciences, University of Mons, Place du Parc 23, B-7000 Mons, Belgium.

${ }^{2}$ Laboratory of Cell Biology, Research Institute for Biosciences, University of Mons, Place du Parc 23, B-7000 Mons, Belgium.

${ }^{3}$ Department of Bioproducts and Biosystems, School of Chemical Engineering, Aalto University, P.O. Box 16100, FI-02150 Espoo, Finland.

${ }^{4}$ Division of Environmental Science and Engineering, Pohang University of Science and

Technology, Pohang 37673, Republic of Korea.

${ }^{5}$ Laboratory for Chemistry of Novel Materials, Research Institute for Materials, Center for Innovation and Research in Materials and Polymers (CIRMAP), University of Mons, Place du Parc 23, B-7000 Mons, Belgium.

${ }^{6}$ Laboratory of Proteomics and Microbiology, Research Institute for Biosciences, University of Mons, Place du Parc 23, B-7000 Mons, Belgium.

$\dagger$ These authors contributed equally to this work, *Corresponding author. Email: Patrick.Flammang@umons.ac.be

\begin{abstract}
In most animals, connective tissues such as the dermis or tendons present invariant mechanical properties, fine-tuned for their structural function. However, echinoderms, a group of sea creatures including sea cucumbers, possess the ability to voluntarily modify the mechanical properties of their connective tissues, which are therefore called mutable collagenous tissues (MCT). Understanding the molecular mechanism underlying MCT mutability is a prerequisite for the development of biomimetic smart dynamic materials. The stiffening and softening cycles of MCTs are made possible by the release of specialized effector proteins. We identified a stiffening factor from the dermis of Holothuria forskali, Hf-(D)Tensilin, and showed that it is localized in the secretory granules of juxtaligamental-like cells, a MCT specific cell type. Using recombinant proteins, we confirmed its effect on the dermis and its aggregation effect on extracted collagen fibrils. A model is proposed for the molecular interactions which mediate collagen fibrils cross-linking by tensilin.
\end{abstract}




\section{Introduction}

Most structural materials from living organisms (e.g., the cell-wall in plants, the cuticle in insects, and the tendons and ligaments in mammals) are composites made up of stiff fibres embedded in a softer non-fibrous matrix. In bilaterian animals, this structural function is generally accomplished by connective tissues, which are complex fibre-reinforced composite structures ${ }^{1,2}$. These tissues are mainly composed of an extracellular matrix (ECM), made up of fibres, proteoglycans and glycoproteins, and cells producing it. The predominant fibrous components are made up of collagen or elastin, insoluble proteins which self-assemble to form long and thin fibrils. The proportions of the different ECM components as well as the length, density and orientation of the fibres determine the mechanical properties of the connective tissues (e.g., skin and artery are more pliant, tendons are stronger, etc.) ${ }^{1-3}$. In adult tissues, these properties are constant and stable except in case of pathology or ageing ${ }^{3-5}$.

Contrary to other animals, echinoderms (e.g., sea stars, sea urchins) possess connective tissues presenting the remarkable ability to change their mechanical properties rapidly (sometimes in less than one second) and reversibly under the control of the nervous system ${ }^{6}$. These tissues are therefore called "Mutable Collagenous Tissues" (MCTs). They are involved in the energy-sparing maintenance of posture which, in turn, can be used in feeding, defence, and many other functions ${ }^{6,7}$. The sea cucumber body wall dermis is a typical MCT. Upon stimulation (by touching the animal with the hand, for instance), the dermis hardens while it becomes soft again when the stimulation stops (Fig. 1A, B). In a few species, an intense stimulation of the animal can even lead to the irreversible disintegration of the body wall ${ }^{6,8}$. In the ECM of this tissue, collagen fibrils are assembled into fibres surrounded by fibrillin microfibrils and arranged into interwoven bundles ${ }^{9,10}$ (Fig. 1C, D). Collagen fibrils are spindleshaped and are not crosslinked together, allowing them to slide past one another when the dermis is in a soft state ${ }^{11-13}$. As in other collagenous tissues, they present proteoglycans (PGs) or only glycosaminoglycans (GAGs) covalently attached to their surface ${ }^{14-16}$. The stiffening and softening cycles of MCTs are made possible by the release of specialized effector proteins by juxtaligamental-like cells (JLCs), a granule-containing cell type specific of MCTs (Fig. 1D). These proteins can reversibly cross-link collagen fibrils and it is now recognized that the different mechanical states reflect the number of cross-links between collagen fibrils, the more the collagen fibrils are connected, the stiffer the MCT will be ${ }^{17}$. In the sea cucumber dermis, according to the species, two or three types of JLCs have been identified, distinguishable by the size and shape of the granules they contain ${ }^{6,16,18}$. 
To date, three putative effector proteins -i.e. tensilin, softenin, and the novel stiffening factor (NSF)- have been identified ${ }^{19-21}$, but only tensilin, a MCT stiffening factor, has been partially characterized. This $33 \mathrm{kDa}$ protein has been isolated from the dermis of Cucumaria frondosa ${ }^{19}$ and Holothuria leucospilota ${ }^{22}$ and complete sequences are available in databases for the dermis of $C$. frondos ${ }^{19}$, the Cuvierian tubules of Holothuria forskali, which have been recently highlighted as a new $\mathrm{MCT}^{23}$, and for Apostichopus japonicus ${ }^{24}$. Tensilin possesses a N-terminal NTR domain homologous to metalloproteinase inhibitors, making it a member of the TIMP (Tissue inhibitor of metalloproteinases) family, which are essential regulators of extracellular matrix turnover and remodelling ${ }^{19}$. Conversely, its C-terminal end lacks homology to any known proteins and is particularly rich in positively charged amino acids that could provide binding to GAGs present on collagen fibrils ${ }^{19}$. The fact that this C-terminal end is susceptible to proteolysis led the authors to hypothesise that, inside the dermis, a protease could detach tensilin from the collagen fibrils, thereby causing the destiffening of the MCT ${ }^{16,19}$. More recently, however, another hypothesis has been proposed by Takehana and co-workers ${ }^{20}$ involving softenin, a putative competitor of tensilin for binding sites present on collagen fibrils of sea cucumber dermis.

Echinoderm MCTs have been presented as a possible source of inspiration for the development of smart dynamic biomaterials which could find applications in tissue engineering and regenerative medicine 7,17,25. Understanding the molecular mechanism underlying MCT mutability is a prerequisite for the development of such inspired biomaterials. In this study, we performed in silico analyses using published tensilin sequences from A. japonicus, from the dermis of $C$. frondosa and from the Cuvierian tubules of $H$. forskali, as well as closely related homologous echinoderm sequences, to identify the tensilin from the dermis of H. forskali, that we named Hf-(D)Tensilin. We demonstrated it is localized in the secretory granules of specific JLCs contained in the dermis, indicating its implication in MCT. Using recombinant proteins, we confirmed the stiffening effect of Hf-(D)Tensilin on the dermis and its aggregation effect on extracted collagen fibrils. Various experiments with full-length and truncated proteins in different conditions allowed us to propose a model for the molecular interactions which mediate collagen fibrils cross-linking by tensilin. 


\section{Results}

\section{Tensilin identification in the dermis of Holothuria forskali}

Using the published protein sequences of tensilins from A. japonicus, from the dermis of $C$. frondosa, and from the Cuvierian tubules of $H$. forskali, a tBLASTn search was performed in the body wall transcriptome of $H$. forskali ${ }^{26}$ to look for transcripts encoding tensilin-like proteins. By considering only hit sequences with an e-value lower than $10^{-15}, 7$ transcripts encoding tensilin-like protein sequences were retrieved. After in silico translation, we performed a sequence-similarity-based clustering analysis using these 7 sequences, the 5 tensilin candidates from $H$. forskali Cuvierian tubules ${ }^{23}$, and a large sample of closely related homologous TIMP-like protein sequences from various echinoderms (Data S1). One subset of sequences (i.e., the "Sea cucumber tensilins" group, Fig. 2A), comprising the tensilins from $A$. japonicus and C. frondosa, consists exclusively of sea cucumber sequences and is separated from all the other sequences in this CLANS clustering analysis with an e-value threshold of $10^{-}$ ${ }^{40}$. For H. forskali, 4 of the 5 tensilin candidates from the Cuvierian tubules and 3 of the 7 tensilin candidates from the dermis belong to this group. A pairwise comparison of the transcripts from these two organs is presented in Table S1. It shows that the 3 tensilin-like transcripts retrieved from the body wall were also present in Cuvierian tubules. However, they differ from the Cuvierian tubule transcript which was identified as coding for the Cuvierian tubule tensilin (Hf-(CT)Tensilin) based on abundance and evidence at the proteomic level ${ }^{23}$. Finally, we performed a multiple amino acid alignment and maximum-likelihood phylogenetic analyses with the sequences from this group as well as with other A. japonicus sequences used in the CLANS analysis (A. japonicus being the only sea cucumber species with an available annotated genome, it gives an overview of the diversity of genes coding for TIMP-like proteins in sea cucumbers). Based on the CLANS analysis, one A. japonicus sequence was selected as outgroup. Phylogenetic analyses indicate that 2 of the tensilin candidates from the dermis of $H$. forskali (encoded by transcripts CL6864 and Unigene31704) form a monophyletic group with the tensilin from the Cuvierian tubules of the same species (Fig. 2B). These three sequences also appear to be closely related to the tensilins of A. japonicus and C. frondosa (Fig. 2B).

We selected the candidate encoded by transcript CL6864 for further analysis because it presents the highest FPKM value in the dorsal body wall transcriptome and the highest percentage of similarity with the 3 published tensilin sequences (Table 1, Fig. S1). This protein was named Holothuria forskali Dermis Tensilin (Hf-(D)Tensilin). Its full-length sequence comprises a 20 -aa-long putative signal peptide followed by a proprotein sequence of 257 aa 
with a predicted molecular mass of $30 \mathrm{kDa}$. Like the other published tensilin sequences, it is characterized by the presence of a netrin-like domain (NTR), from the TIMP family, at its Nterminal end (Fig. 3, Fig. S2) ${ }^{19,22}$. The motif His-Pro-Gln (HPQ), highly conserved across TIMPs (including published tensilins) ${ }^{27,28}$, is present in the N-terminal part of Hf-(D)Tensilin (Figs 3 and S1). To the best of our knowledge, the function of this motif in the functioning of TIMPs is not known yet. Finally, as described in the tensilin from the dermis of C. frondosa ${ }^{19}$, Hf-(D)Tensilin possesses a positive charge cluster at its C-terminal end (Figs 3 and S1).

To confirm the expression and localisation of Hf-(D)Tensilin in the body wall of $H$. forskali, polyclonal antibodies were raised against two peptides (DGMKLGRKKTGKTI and NPHKSREFSEIEDC) (Fig. S2). Immunofluorescence investigations indicate a specific labelling in the dermis with both antibodies, at the level of elongated cells reminiscent of juxtaligamental-like cells (JLCs) (Fig. 4A, Fig S3). In TEM, we observed three types of JLCs with cell processes insinuating between the collagen fibres of the dermis -type 1 JLCs containing small spherical granules (diameter ranging between 70 and $180 \mathrm{~nm}$ ) of medium electron-density, type 2 JLCs containing middle-sized elongated granules (150-300 x 300-650 $\mathrm{nm}$ ) of medium electron-density, and type 3 JLCs containing very electron-dense large spherical granules (diameter ranging between $600 \mathrm{~nm}$ and $1 \mu \mathrm{m}$ ) (Fig. 4 B,C, Fig. S4)- as already described in $C$. frondosa ${ }^{13,18}$. Type 1 and type 2 JLCs were always observed close to each other while type 3 JLCs were not always associated with them (Fig. 4C). Immunocytochemistry localized Hf-(D)Tensilin in the granules of types 2 JLCs (Fig. 4 D,E).

\section{Production and testing of recombinant tensilins}

In order to investigate the molecular function of Hf-(D)Tensilin, we recombinantly produced the full-length and truncated proteins in the bacterium Escherichia coli (Fig. S5). Truncated proteins were designed as follows: (1) the first 15 aa of the protein were removed to investigate the importance of the highly conserved HPQ motif, (2) the C-terminal 15 aa were removed because this region is rich in negatively charged Glu residues, and (3) the C-terminal 40 aa were removed as this part of the protein comprises the 15 aa removed in (2) as well as another region rich in positively charged Arg and Lys residues, which has been proposed as a potential binding site to GAGs present on collagen fibrils ${ }^{19}$ (Fig S2). The identity of the produced proteins (namely, rTensilin, rTensilin-15N, rTensilin-15C, and rTensilin-40C) was confirmed by Western blot and/or via in-solution trypsinolysis followed by LC-MS/MS analysis of the 
resulting peptides (Fig. 5A, Fig. S2). The full-length rTensilin presented an apparent molecular weight of $\sim 37 \mathrm{kDa}$, like the native Hf-(D)Tensilin, while truncated proteins presented lower apparent molecular weights ( $\sim 36 \mathrm{kDa}$ for rTensilin-15N, $\sim 35 \mathrm{kDa}$ for rTensilin-15C, and 30kDa for rTensilin-40C), as expected (Fig. 5A).

After purification, the full-length rTensilin presented the expected biological effect as it stiffened the dermis in vitro. Indeed, the addition of rTensilin to pieces of dermis previously bathed in calcium-free artificial seawater (ASW-EGTA) to induce their soft state ${ }^{18}$ increased their stiffness, strength and toughness (Fig. 5B,C, Fig. S6). These results are consistent with those reported for extracts of dermis containing native tensilin in C. frondosa ${ }^{19}$ and in $H$. leucospilota ${ }^{22}$.

The ability of the 4 recombinant proteins to bind to and aggregate collagen fibrils was assessed using aggregation assays. Collagen fibrils were extracted from the dermis of $H$. forskali according to a protocol adapted from Tamori et al. ${ }^{22}$. SEM confirmed the collagenous nature of the extracted fibrils, which present a characteristic banding pattern of about $60 \mathrm{~nm}$ in periodicity (Fig. 6A). Aggregation of a $100 \mu \mathrm{l}$ suspension of collagen fibrils extracted from about $10 \mathrm{mg}$ of dermis started after the addition of $55 \mu \mathrm{g} / \mathrm{ml}(1.8 \mu \mathrm{M})$ of rTensilin (Fig. $6 \mathrm{C}$ ). Noteworthily, the addition of the same concentration of BSA (Fig. 6D) or of another recombinant protein with a C-terminal 6xHis Tag (Fig. S7) did not trigger the aggregation of collagen fibrils. We confirmed with this test the collagen fibril aggregation capacity of rTensilin, also described with the native protein in C. frondosa and H. leucospilota ${ }^{19,22}$. Moreover, the aggregation capacity of rTensilin is similar to that of native tensilin from $H$. leucospilota, for which $20 \mu \mathrm{g} / \mathrm{ml}$ of tensilin was necessary to aggregate $20 \mu \mathrm{l}$ of collagen fibrils extracted from about $1.4 \mathrm{mg}$ of body wall ${ }^{22}$. The addition of rTensilin- $15 \mathrm{~N}$ on collagen fibrils also induced their aggregation whereas no aggregation effect was observed with rTensilin-15C and rTensilin-40C, indicating that the C-terminal part of tensilin is essential for its aggregation effect on collagen fibrils (Fig. 6E-G).

\section{Molecular interactions involved in the collagen aggregation activity of tensilin}

To further understand the type of interactions contributing to the aggregation effect of tensilin on collagen fibrils, suspensions of fibrils were pre-mixed with different test solutions before the addition of rTensilin, or aggregates obtained by mixing collagen fibrils with rTensilin were subsequently submitted to the same test solutions (Table 2, Fig. S9). As a general rule, the tests 
showed that it was easier to prevent the formation of aggregates than to destabilize already formed aggregates. The addition of heparin (a sulfated GAG), of the negatively charged amino acids Asp and Glu, or of the positively charged amino acids Arg and Lys, all prevented the formation of aggregates and completely and quickly destabilized previously formed aggregates. $\mathrm{NaCl}, \mathrm{MgCl}_{2}, 1,6$-hexanediol and tetraethylammonium chloride (TEA) also had an inhibitory impact, although to a lesser extent (incomplete or slower effect). Conversely, the neutral amino acid Gly and the cation chelators EGTA and EDTA had no impact on the aggregation effect of rTensilin (Table 2, Fig. S9). The fact that both the negatively charged heparin and the charged amino acids prevent rTensilin from aggregating collagen fibrils seems, at this point, to corroborate the hypothesis of Tipper et al. ${ }^{19}$ suggesting that the richly basic series of residues at the C-terminal tail of tensilin could act as a GAG-binding site. The moderate effect observed for $\mathrm{NaCl}$ and $\mathrm{MgCl}_{2}$ could be attributed to the fact that salts are disruptors of electrostatic interactions. Additionally, some hydrophobic and cation- $\pi$ interactions could be involved in the formation of the aggregates since the addition of 1,6-hexanediol ${ }^{29}$ and TEA ${ }^{30}$, respectively, slows down the formation of the aggregate. Results obtained with EGTA and EDTA, on the other hand, confirm the observation of Trotter and Koob ${ }^{18}$ that the interaction between tensilin and collagen fibrils is not mediated by cations, such as $\mathrm{Ca}^{2+}$. In another experiment in which rTensilin was added to collagen fibrils previously treated with $\mathrm{HCl}$ to remove sulfate groups from their surface GAGs, no aggregate was observed (Fig. 6H). The analysis of these fibrils in SEM showed that the treatment did not affect the fibril morphology (Fig. S8).

To investigate more specifically the interactions between tensilin and collagen fibrils, we collected the fibrils, whether aggregated or not, by centrifugation after the aggregation tests, resuspended them in SDS sample buffer and analysed the extracts by SDS-PAGE. By doing so, if tensilin is attached to the collagen fibrils, we expect to observe the corresponding band on the gel (the SDS sample buffer would disrupt its non-covalent interaction with the fibrils) while if tensilin is not attached to the collagen fibrils during the aggregation tests, it will remain in the supernatant and will not be co-precipitated with the fibrils. The presence of a protein band with the appropriate molecular weight on the SDS-PAGE gel when both full-length and truncated rTensilins were mixed with collagen fibrils indicates that all recombinant proteins bind to collagen (Fig. S10 lanes 2-5), even those which do not cause the aggregation of fibrils. As proposed by Tipper et al. ${ }^{19}$, rTensilin would in fact bind to sulfated GAG-containing molecules known to be covalently attached to holothuroid collagen fibrils ${ }^{14-16}$. Indeed, when collagen fibrils were treated with $\mathrm{HCl}$ to remove sulfate groups from the GAGs, rTensilin was 
not able to bind to the fibrils anymore (Fig. S10 lane 10). In addition, we showed that the addition of heparin prevents the binding of rTensilin to the collagen fibrils (Fig. S10 lane 6). As the removal of the 15 first or the 15 or 40 last amino acids of the protein does not prevent the binding of rTensilin to collagen fibrils, neither the HPQ motif nor the C-terminus (including the positive charge cluster) seem to be important for this function. These results indicate that the fibril-binding site of tensilin would reside either in the remaining part of the NTR domain or in the unannotated part of the protein before the 40 last amino acids (Fig. 3). Re-examination of the sequence of Hf-(D)Tensilin revealed a consensus sequence for GAG recognition [XBBBXXBX] where $\mathrm{B}$ is a basic residue and $\mathrm{X}$ is a hydropathic residue ${ }^{31,32}$. This putative GAG-binding motif, [GRKKTGKT], is located within the NTR domain (Figs 7 and S2). As, coincidentally, this binding sequence is comprised in one of the two peptides used to generate antibodies (DGMKLGRKKTGKTI), we tested the effect of this peptide on rTensilin-mediated collagen fibril aggregation and used the other peptide (NPHKSREFSEIEDC) as a control. At a concentration of $25 \mu \mathrm{M}$ (more than 10 times the concentration of rTensilin used in the assay), neither of these 2 peptides inhibited the formation of collagen fibril aggregates, nor did they lead to the destabilization of pre-formed aggregates (Table 2, Fig. S9). They also did not prevent the binding of rTensilin to collagen fibrils (Fig. S10 lanes 14 and 15). Moreover, this GAGbinding motif does not appear to be conserved in orthologous sea cucumber tensilins (Figs 7 and S1). These observations indicate that this short sequence is probably not sufficient to bind GAGs. Modelling the 3D structure of the NTR TIPM-like domain of tensilin revealed that this motif is framed by two others to form a large positively charged area on one side of the protein (Fig. 7), suggesting that the interaction of tensilin with sulfated GAGs could be based instead on the tertiary structure of the NTR domain. The occurrence of basic residues at similar locations in the different tensilins (even though sequences are not strictly conserved) suggests a similar binding mechanism (Fig. 7). This 3D complementarity between the NTR domain and GAGs could presumably produce a high affinity binding between rTensilin and collagen fibrils as it cannot be inhibited by high $\mathrm{NaCl}$ concentrations (i.e., $2.5 \mathrm{M}$; Fig. S10 lane 11), although this concentration prevented the aggregation effect (Fig. S9).

If the Arg and Lys-rich C-terminal end of tensilin does not provide binding to GAGs present on collagen fibrils, then it could be involved instead in interactions occurring between two or more molecules of tensilin in order to cross-bridge collagen fibrils. The C-terminal part of Hf-(D)Tensilin indeed presents a series of negatively charged amino acids (removed in rTensilin-15C) preceded by a series of positively charged residues (removed in rTensilin-40C). 
The head to tail interaction of these two regions together through electrostatic interactions could therefore allow the dimerization or oligomerization of the protein. The addition of positively or negatively charged amino acids or the removal of these parts (as in rTensilin-15C and rTensilin40C) indeed inhibits the formation of cross-bridges between collagen fibrils, hence their aggregation. High salt concentrations, 1,6 hexanediol and TEA also reduce the aggregation of fibrils indicating that, in addition to electrostatic interactions, hydrophobic and cation- $\pi$ interactions could also be involved in the oligomerization of tensilin. Interestingly, all tensilins described so far possess one or, most often, two aromatic amino acids (phenylalanine or tyrosine) among their 3 last residues (Figs 3 and S1). These residues could be involved in cation$\pi$ interactions with the Arg and Lys residues of the C-termini of other tensilin molecules (Tyr and $\mathrm{Phe}$ ) or in hydrophobic interactions (Phe).

\section{Discussion}

Tissue inhibitors of metalloproteinases (TIMPs) are essential regulators of extracellular matrix turnover and remodelling ${ }^{33}$. It has been proposed that the coordinated action of TIMPcontaining proteins, including tensilin, and matrix metalloproteinases (MMP) could be responsible of the rapid changes in mechanical properties of echinoderm MCTs, as it is the case in the cervix, the only mammalian MCT ${ }^{19,34,35}$. Clouse et al. ${ }^{33}$ showed that the number of TIMP genes per taxon is significantly different across the 5 echinoderm classes: the average proportion of TIMP genes is 3 to 8 times higher in sea cucumbers than in the other classes. According to these authors, this is presumably linked to the importance of MCTs in sea cucumbers in which they are involved in evisceration or autotomy, but also in some species in the liquefaction of the body wall ${ }^{28}$. Our clustering analysis corroborated the high diversity of TIMP-like proteins across the holothuroid class and highlighted several isolated clusters consisting mostly or exclusively of sea cucumber transcripts. Among them, one specific group, already pointed out in a phylogenetic analysis of echinoderm TIMP-like proteins ${ }^{36}$, comprises all the tensilins described to date. In H. forskali, like in A. japonicus, several tensilin transcripts apparently co-exist, but the tensilin expressed in the dermis is different from the one identified in the Cuvierian tubules. This suggest that some tensilin variants could be tissue specific, a hypothesis deserving more investigations in the future.

Like the tensilin of $C$. frondosa ${ }^{19}$, Hf-(D)Tensilin is a secreted extracellular matrix protein comprising a N-terminal NTR TIMP-like domain and an unannotated C-terminus which 
bears a positive charge cluster. It is produced by a specific type of juxtaligamental-like cells (i.e., type 2 JLCs) containing ellipsoidal secretory granules. To the best of our knowledge, this is the first time that the localization of tensilin within the secretory granules of a specific type of JLCs is confirmed ${ }^{16,19}$. Recombinant Hf-(D)Tensilin produced in E. coli both stiffened pieces of dermis which were in the soft state and aggregated isolated collagen fibrils. Using truncated rTensilins as well as various solutions, we were able to show that, contrary to the currently admitted hypothesis ${ }^{16,19}$, the positive charge cluster of the C-terminus does not mediate the binding of tensilin to the GAG-containing molecules covalently attached to collagen fibrils ${ }^{14,15}$, but is important for fibril aggregation. The binding of tensilin to sulfated GAGs would therefore rather involve the NTR domain, which was present in all tested truncated rTensilins. In the protein procollagen C-proteinase enhancer 1 (PCPE-1), it has been shown that the NTR domain, which is homologous to the N-terminal domain of TIMPs ${ }^{37}$, interacts with the negatively charged GAG chains of syndecans ${ }^{38}$. The NTR domain of PCPE1 also binds to heparin with a high affinity ${ }^{39}$. Even though it does not contain any linear consensus sequence proposed for GAG binding, electrostatic surface representation of this domain shows that several basic amino acids are clustered on one face of the molecule, forming positively charged clusters that may bind heparin ${ }^{40}$. Such extensive binding motifs, crossing multiple peptide strands, are known to produce very high affinity binding to GAGs in some proteins ${ }^{41}$. A similar mechanism is proposed for Hf-(D)Tensilin.

Based on the results obtained in our study, we can refine the model proposed by Wilkie ${ }^{16}$ to explain MCT's stiffening induced by tensilin. In this model, spindle-shaped collagen fibrils assemble into fibres but are not covalently crosslinked together, allowing them to slide past one another when the dermis is in a soft state. These fibrils are coated with sulfated GAG-containing molecules covalently bound to their surface ${ }^{14,15}$. To stiffen the dermis, tensilin is released from type 2 JLCs. Its N-terminal NTR domain specifically binds the sulfated GAGs whereas its Cterminal end is involved in the formations of dimers or oligomers, therefore allowing crossbridging of the collagen fibrils (Fig. 8). This, in turn, increases interfibrillar stiffness, as demonstrated by Mo et al. ${ }^{17}$ at the nanoscale. We expect that the binding of tensilin to collagen fibrils could also be achieved with collagen from other organisms, provided their fibrils are also coated with sulfated GAGs, opening the way to various applications in which mutability of collagen-based materials would be required. For example, tensilin has the potential to be used as a modulator in dynamic collagen-based scaffolds in biomedical applications. 


\section{Methods}

\section{Sea cucumber collection and maintenance}

Adult individuals of Holothuria forskali (Delle Chiaje, 1823) were obtained from the Observatoire Océanologique de Banyuls-sur-Mer (Pyrénées-Orientales, France) or from the Station Biologique de Roscoff (Finistère, France). Animals were then transported to the laboratory of Biology of Marine Organisms and Biomimetics (University of Mons, Belgium), where they were kept in a re-circulating aquarium $\left(13^{\circ} \mathrm{C}, 33 \%\right.$ salinity $)$.

\section{Tensilin identification and in silico characterization}

Tensilin sequences from A. japonicus, from the dermis of $C$. frondosa and from the Cuvierian tubules of $H$. forskali were retrieved from NCBI (accession numbers ALD83456, AAK61535 and AQR59058, respectively) and were used for a tBLASTn search in the dorsal body wall transcriptome from $H$. forskali ${ }^{26}$. Only transcripts identified with an e-value lower than $10^{-15}$ were considered and their FPKM (Fragments Per Kilobase of transcript per Million mapped reads) values were used to estimate their relative abundance in the body wall transcriptome ${ }^{42}$. The transcript sequences were translated into protein sequences by using the Translate tool of the ExPASy Proteomics Server ${ }^{43}$.

The 7 selected sequences from the body wall of $H$. forskali, the tensilins from $A$. japonicus and from $C$. frondosa dermis, the 6 tensilin candidates from H. forskali Cuvierian tubules ${ }^{23}$ and a large sample of closely related homologous echinoderm sequences were analyzed using a sequence-similarity-based clustering approach based on BLASTp e-values and using the CLANS software ${ }^{44}$. The additional echinoderm sequences were collected using the web platform EchinoDB, a repository of orthologous transcripts from echinoderms (http://echinodb.uncc.edu) ${ }^{45}$. Based on the CLANS clustering, a subset of predicted proteins of interest, called sea cucumber tensilins, was selected to perform a multiple amino acid alignment using MAFFT algorithm (v.7.450, E-INS-i, scoring matrix: Blosum 62, gap open penalty: 3) ${ }^{46}$ implemented in Geneious Prime ${ }^{\circledR}$ 2019.1.1. Pairwise sequence identity and similarity were calculated from trimmed multiple sequence alignments using SIAS web tool ${ }^{47}$. Phylogenetic analyses were then conducted using the maximum-likelihood method. Prior to the phylogenetic reconstructions, alignment trimming was performed using TrimAl ${ }^{48}$ implemented in the MetaPiga software (v. 3.1) ${ }^{49}$. Maximum-likelihood phylogenetic tree was reconstructed using the PhyML software (v. 3.3) ${ }^{50}$. Best-fit model analysis was conducted beforehand using Smart 
Model Selection ${ }^{51}$. The LG substitution model was selected assuming an estimated proportion of invariant sites (of 0.056) and four gamma-distributed rate categories to account for rate heterogeneity across sites. The gamma shape parameter was estimated directly from the data (gamma $=1.948)$. Reliability for internal branch was assessed using the bootstrapping method (1000 bootstrap replicates). Based on the CLANS analysis, one sequence of A. japonicus from outside the group "sea cucumber tensilins" was chosen as outgroup. The final tree was visualized in FigTree software (v1.4.4) ${ }^{52}$.

Finally, one tensilin-like protein (hereby named Holothuria forskali Dermis Tensilin, Hf-(D)Tensilin) was selected for further analyses based on similarity with other tensilins and phylogenetic results obtained. For this protein, the presence of specific domains was predicted by the Conserved Domain Database ${ }^{53}$, the presence of a signal peptide was predicted using SignalP $5.0{ }^{54}$, the amino acid composition and the molecular weight values were determined using the ProtParam tool from Expasy ${ }^{43}$, and a 3D model was generated using SWISS-MODEL 55. The sequence of Hf-(D)Tensilin has been deposited in GenBank database under accession number XX.

\section{Antibody production}

Two peptides (DGMKLGRKKTGKTI and NPHKSREFSEIEDC) were selected from Hf(D)Tensilin on the basis on their potential for successful synthesis and immunogenicity for polyclonal antibody production in rabbits (Genscript, Piscataway, New Jersey, USA). The antibodies were isolated from the crude serum by affinity purification using the synthetic peptides (Genscript).

\section{Immunohistochemistry}

Pieces of body wall were collected by animal dissection after anaesthesia by incubation in seawater containing $0.1 \%$ propylene phenoxetol for $1 \mathrm{~h}$ at room temperature, and subsequently fixed for $4 \mathrm{~h}$ at room temperature in $4 \%$ (wt/vol) paraformaldehyde in phosphate-buffered saline (PBS; pH 7.4). Then, they were rinsed in PBS, dehydrated through an ethanol series, embedded in paraffin and cut transversely into $4 \mu \mathrm{m}$ thick sections as previously described ${ }^{23}$. Some sections were stained with Heidenhain Azan trichrome while the others were subjected to an indirect immunofluorescence protocol as follows. Antigen retrieval was achieved by incubation in a solution containing $0.05 \%$ (wt/vol) trypsin (Sigma) and $0.1 \%$ (wt/vol) $\mathrm{CaCl}_{2}$ for $15 \mathrm{~min}$ at $37{ }^{\circ} \mathrm{C}$. The sections were probed with the purified anti-DGMKLGRKKTGKTI and anti- 
NPHKSREFSEIEDC antibodies diluted 1:100, followed by Alexa Fluor 594-conjugated goat anti-rabbit immunoglobulin (Invitrogen), and observed by using an Olympus FluoView FV1000 confocal microscope. Control reactions were performed by saturating the antibodies with the corresponding peptide.

\section{Immunocytochemistry}

Pieces of body wall were fixed for $3 \mathrm{~h}$ at $4{ }^{\circ} \mathrm{C}$ in $3 \%$ (vol/vol) glutaraldehyde in cacodylate buffer $\left(0.1 \mathrm{M}, \mathrm{pH} 7.8\right.$; adjusted to $1,030 \mathrm{mOsm}^{-1}$ with $\left.\mathrm{NaCl}\right)$. They were then rinsed in cacodylate buffer and post-fixed in $1 \%$ osmium tetroxide in the same buffer. After rinsing again in cacodylate buffer, the samples were dehydrated through an ethanol series and embedded in Spurr resin. Ultrathin transverse sections $(\sim 80 \mathrm{~nm})$ were cut with a Leica Ultracut UCT ultramicrotome equipped with a diamond knife. Some sections were contrasted with uranyl acetate and lead citrate while others were subjected to an indirect immunogold labelling as follows. They were probed with the two purified antibodies diluted 1:100, followed by goat anti-rabbit immunoglobulins conjugated to 15-nm gold particles (BB International). Control reactions were performed by saturating the antibodies with the corresponding peptide. All sections were observed with a Zeiss LEO 906E transmission electron microscope.

\section{Production and purification of recombinant tensilin}

The coding sequence for Hf-(D)Tensilin or sequences coding for $\mathrm{N}$-terminally truncated protein (lacking the first 15 amino acids) or for C-terminally truncated proteins (lacking the terminal 15 and 40 amino acids) were inserted in pET-28a (+) protein expression vector (Novagen) in frame with a C-terminal $6 \times$ His-tag coding sequence. The recombinant proteins (namely, rTensilin, rTensilin-15N, rTensilin-15C, and rTensilin-40C) were expressed in the Escherichia coli $\mathrm{C} 2566$ strain (New England Biolabs) and purified using a Ni Sepharose 6 Fast Flow column (GE Healthcare). Additional information is provided in SI Appendix, Materials and Methods.

\section{Western blotting}

Pieces of dermis were rapidly dissected as described above. They were homogenized in a 1.5 M Tris- $\mathrm{HCl}$ buffer (pH 7.8) containing 0.5 M DTT, $5 \mathrm{M}$ urea, $2 \%$ (wt/vol) SDS, and protease inhibitors (cOmplete ${ }^{\mathrm{TM}}$, EDTA-free Protease Inhibitor Cocktail, Roche) using a Heidolph Silent 
Crusher-M homogeniser. Proteins extracted from the dermis as well as recombinant proteins were submitted to SDS-PAGE. After electrophoresis, proteins were transferred onto PVDF membranes (GE Healthcare) using $25 \mathrm{mM}$ Tris, $192 \mathrm{mM}$ glycine, 0.05\% (wt/vol) SDS, 20\% methanol ( $\mathrm{vol} / \mathrm{vol})$ as transfer buffer. The blots were then immunodetected as previously described ${ }^{23}$ using the anti-DGMKLGRKKTGKTI and the anti-NPHKSREFSEIEDC antibodies diluted 1:5000, followed by HRP-conjugated anti-rabbit antibodies (Invitrogen) and chemiluminescence detection (ECL Western Blotting Substrate or SuperSignal ${ }^{\mathrm{TM}}$ West Femto Maximum Sensitivity Substrate, Pierce). Control reactions were performed by substituting the primary antibody with pre-immune serum diluted 1:5000.

\section{Extraction of collagen fibrils from the dermis}

The protocol was adapted from Tamori et al. ${ }^{22}$. Pieces of body wall of about $1 \mathrm{~cm}^{3}$ were rapidly dissected from one or several sea cucumber(s) after anaesthesia. The epidermis was removed, and the pieces of dermis were immediately frozen at $-80^{\circ} \mathrm{C}$ for a minimum of $3 \mathrm{~h}$ in 2 volumes of $20 \mathrm{mM}$ Tris-HCl, $2 \mathrm{M} \mathrm{NaCl}, 10 \mathrm{mM}$ EGTA, pH 8.0 (buffer 1) containing protease inhibitors (cOmplete ${ }^{\mathrm{TM}}$, EDTA-free Protease Inhibitor Cocktail, Roche). They were then thawed on ice, cut into smaller pieces, and homogenised in the same buffer using a Heidolph Silent Crusher$\mathrm{M}$ homogeniser. The homogenate was frozen again overnight at $-80^{\circ} \mathrm{C}$. After thawing on ice, the dermis extract was centrifuged for $30 \mathrm{~min}$ at $26,900 \mathrm{~g}$. The pellet was used to extract collagen fibrils as follows. The pellet was suspended in $3 \mathrm{M} \mathrm{NaCl}$ and centrifuged at $26,900 \mathrm{~g}$ for $10 \mathrm{~min}$ at $4^{\circ} \mathrm{C}$. This cycle of centrifugation and re-suspension was repeated four times. The pellet was then suspended in milliQ water and four new cycles of centrifugation and resuspension were performed. The last pellet was suspended in $3 \mathrm{M}$ guanidine- $\mathrm{HCl}$ and the resulting suspension was centrifuged at $26,900 \mathrm{~g}$ for $10 \mathrm{~min}$ at $4^{\circ} \mathrm{C}$. The resulting pellet was suspended in $20 \mathrm{mM}$ Tris-HCl, $0.5 \mathrm{M} \mathrm{NaCl}, 2 \mathrm{mM}$ EGTA, pH 8.0 (buffer 2). The cycle of centrifugation and re-suspension in this buffer was repeated three times to remove guanidine$\mathrm{HCl}$. Trypsin $(1 \mu \mathrm{g} / \mathrm{ml})$ was added to the final suspension, and the suspension was incubated for $12 \mathrm{~h}$ at $25^{\circ} \mathrm{C}$. After centrifugation, the pellet was washed four times in buffer 2 to remove trypsin. Aliquots of collagen fibrils in buffer 2 were stored at $-80^{\circ} \mathrm{C}$. SEM was used to confirm the presence and purity of collagen fibrils. Additional information is provided in SI Appendix, Materials and Methods. 


\section{Collagen fibril aggregation assays}

The protocol was adapted from Tamori et al. ${ }^{22}$ and Trotter et al. ${ }^{56}$. A $100 \mu$ l suspension of collagen fibrils extracted from about $10 \mathrm{mg}$ of dermis was mixed with different quantities of full-length or truncated rTensilin dialysed against buffer 2 and the formation of aggregates of collagen fibrils was observed by eye. Bovine serum albumin (BSA) was used as a negative control. Then, the effects of different chemicals on the formation or stability of collagen fibril aggregates were tested. In the former case, the suspension of collagen fibrils was first mixed with test solutions to obtain buffer 2 supplemented with (1) $4 \%$ (wt/vol) heparin, (2) $17 \mathrm{mM}$ arginine, (3) $17 \mathrm{mM}$ lysine, (4) $2.5 \mathrm{M} \mathrm{NaCl}$, (5) $0.35 \mathrm{M} \mathrm{MgCl}_{2}$, (6) $17 \mathrm{mM}$ glycine, (7) $17 \mathrm{mM}$ aspartic acid, (8) 17 mM glutamic acid, (9) 20 mM EGTA, (10) 20 mM EDTA, (11) $0.21 \mathrm{M}$ $(2.5 \%(\mathrm{wt} / \mathrm{vol}))$ 1,6 hexanediol, (12) $0.15 \mathrm{M}(2.5 \%$ (wt/vol)) tetraethylammonium chloride (TEA), or (13) $25 \mu \mathrm{M}$ of the peptide DGMKLGRKKTGKTI or of the peptide NPHKSREFSEIEDC before the addition of rTensilin. In the latter case, pre-formed aggregates were mixed with the test solutions to obtain the same final concentrations. All the solutions presented a $\mathrm{pH}$ ranging between 7.0 and 8.0 (for glutamic acid and aspartic acid, the $\mathrm{pH}$ was adjusted with $\mathrm{NaOH}$ ). Aggregation tests were also performed by adding rTensilin to collagen fibrils previously treated to remove sulfate groups from their surface GAGs following the protocol from $\mathrm{Wu}$ et al. ${ }^{57}$. The integrity of the treated fibrils was controlled using SEM as explained in SI Appendix, Materials and Methods. At the end of the aggregation tests, the collagen fibrils, whether aggregated or not, were collected by centrifugation, resuspended in SDS sample buffer and the resulting extracts were submitted to SDS-PAGE.

\section{Mechanical testing}

Pieces of dermis $(4 \times 4 \times 30 \mathrm{~mm})$ dissected from the dorsal region of one individual previously anaesthetized for $1 \mathrm{~h}$ at $4^{\circ} \mathrm{C}$ were incubated for $90 \mathrm{~min}$ at room temperature in $1.3 \mathrm{ml}$ of calcium free artificial sea water (10 mM MOPS, $0.5 \mathrm{M} \mathrm{NaCl}, 50 \mathrm{mM} \mathrm{MgCl}_{2}, 10 \mathrm{mM} \mathrm{KCl}, 4 \mathrm{mM}$ EGTA, pH 7.8; ASW-EGTA). Then, rTensilin was added at a final concentration of $12.5 \mu \mathrm{g} / \mathrm{ml}$ and the pieces of body wall were incubated overnight in this solution. Control samples were kept in ASW-EGTA for the same duration. Tensile tests were then performed with a Mecmesin AFG $10 \mathrm{~N}$ electronic force gauge fitted on a Mecmesin VersaTest motorized stand (Horsham, UK). Pieces of body wall were attached on the stand and force gauge by two cotton threads tied around their ends and were pulled at a constant rate $\left(25 \mathrm{~mm} \mathrm{~min}^{-1}\right)$ until failure. Failure never 
occurred at the knots. Data were continuously recorded as force-extension curves, which were then converted into stress-strain curves ${ }^{58,59}$. Several material properties of the dermis, i.e. extensibility, strength, stiffness and toughness, were calculated according to the formulae of Vogel $^{2}$ (additional information is provided in SI Appendix, Materials and Methods). The mechanical tests were performed on 6 pieces of dermis for each solution, all dissected from a same individual.

\section{References}

1. Holzapfel, G.A., Gasser, T.C. \& Ogden, T.C. A New Constitutive Framework for Arterial Wall Mechanics and a Comparative Study of Material Models. J. Elast. 61, 1-48 (2000).

2. Vogel, S. Comparative Biomechanics - Life's physical world (Princeton University Press, Princeton, NJ, 2003).

3. Culav, E.M., Clark, C.H. \& Merrilees, M.J. Connective tissues: matrix composition and its relevance to physical therapy. Phys. Ther. 79, 308-319 (1999).

4. Bailey, A.J., Gathercole, L.J., Dlugosz, J., Keller, A. \& Voyle, C.A. Proposed resolution of the paradox of extensive crosslinking and low tensile strengh of Cuvierian tubule collagen from the sea cucumber Holothuria forskali. Int. J. Biol. Macromol. 4, 329-334 (1982).

5. Knott, L., Tarlton, J.F. \& Bailey, A.J. Chemistry of collagen cross-linking: biochemical changes in collagen during the partial mineralization of turkey leg tendon. Biochem. J. 322, 535-542 (1997).

6. Wilkie, I.C. Mutable collagenous tissues: extracellular matrix as mechano-effector. Echinoderm Studies. 5, 61-102 (1996).

7. Trotter, J.A., Tipper, J., Lyons-Levy, G., Chino, K., Heuer, A.H., Liu, Z., Mrksich, M., Hodneland, C., Dillmore, W.S., Koob, T.J., Koob-Emunds, M.M., Kadler, K. \& Holmes, D. Towards a fibrous composite with dynamically controlled stiffness: lessons from echinoderms. Biochem. Soc. Trans. 28, 357-362 (2000).

8. Motokawa, T. The stiffness change of the holothurian dermis caused by chemical and electrical stimulation. Comp. Biochem. Physiol. C. 70, 41-48 (1981).

9. Motokawa, T. Fine structure of the dermis of the body wall of the sea cucumber, Stichopus chloronotus, a connective tissue which changes its mechanical properties. Galaxea 1, 55-64 (1982).

10. Thurmond, F. \& Trotter, J. Morphology and biomechanics of the microfibrillar network of sea cucumber dermis. J. Exp. Biol. 199, 1817-1828 (1996).

11. Motokawa, T. Connective tissue catch in Echinoderms. Biol. Rev. 59, 255-270 (1984). 
12. Trotter, J.A. \& Koob, T.J. Collagen and proteoglycan in a sea urchin ligament with mutable mechanical properties. Cell. Tissue Res. 258, 527-539 (1989).

13. Koob, T.J., Koob-Emunds, M.M. \& Trotter, J.A. Cell-derived stiffening and plasticizing factors in sea cucumber (Cucumaria frondosa) dermis. J. Exp. Biol. 202 (Pt 17), 2291-2301 (1999).

14. Trotter, J.A., Thurmond, F.A. \& Koob, T.J. Molecular structure and functional morphology of echinoderm collagen fibrils. Cell. Tissue Res. 275, 451-458 (1994).

15. Trotter, J.A., Lyons-Levy, G., Thurmond, F.A. \& Koob, T. J. Covalent composition of collagen fibrils from the dermis of the sea cucumber, Cucumaria frondosa, a tissue with mutable mechanical properties. Comp. Biochem. Physiol. 112A, 463-478 (1995).

16. Wilkie, I.C. Mutable collagenous tissue: overview and biotechnological perspective. Prog. Mol. Subcell. Biol. 39, 221-250 (2005).

17. Mo, J., Prévost, S.F., Blowes, L.M., Egertová, M., Terrill, N.J., Wang, W., Elphick, M.R. \& Gupta, H.S. Interfibrillar stiffening of echinoderm mutable collagenous tissue demonstrated at the nanoscale. Proc. Natl. Acad. Sci. 113, E6362-E6371 (2016).

18. Trotter, J. \& Koob, T. Evidence that calcium-dependent cellular processes are involved in the stiffening response of holothurian dermis and that dermal cells contain an organic stiffening factor. J. Exp. Biol. 198, 1951-1961 (1995).

19. Tipper, J.P., Lyons-Levy, G., Atkinson, M.A. \& Trotter, J.A. Purification, characterization and cloning of tensilin, the collagen-fibril binding and tissue-stiffening factor from Cucumaria frondosa dermis. Matrix Biol. 21, 625-635 (2002).

20. Takehana, Y., Yamada, A., Tamori, M. \& Motokawa, T. Softenin, a novel protein that softens the connective tissue of sea cucumbers through inhibiting interaction between collagen fibrils. PLoS One 9, e85644 (2014).

21. Yamada, A., Tamori, M., Iketani, T., Oiwa, K. \& Motokawa, T. A novel stiffening factor inducing the stiffest state of holothurian catch connective tissue. J. Exp. Biol. 213, 3416-3422 (2010).

22. Tamori, M., Yamada, A., Nishida, N., Motobayashi, Y., Oiwa, K. \& Motokawa, T. Tensilinlike stiffening protein from Holothuria leucospilota does not induce the stiffest state of catch connective tissue. J. Exp. Biol. 209, 1594-1602 (2006).

23. Demeuldre, M., Hennebert, E., Bonneel, M., Lengerer, B., Van Dyck, S., Wattiez, R., Ladurner, P. \& Flammang, P. Mechanical adaptability of sea cucumber Cuvierian tubules involves a mutable collagenous tissue. J. Exp. Biol. 220, 2108-2119 (2017).

24. Li, L. \& He, C. tensilin [Apostichopus japonicus]. GenBank https://www.ncbi.nlm.nih.gov/protein/ALD83456.1 (2015).

25. Barbaglio, A., Tricarico, S., Ribeiro, A., Ribeiro, C., Sugni, M., Di Benedetto, C., Wilkie, I.C., Barbosa, M., Bonasoro, F. \& Candia Carnevali, M.D. The mechanically adaptive connective tissue of echinoderms: its potential for bio-innovation in applied technology and ecology. Mar. Environ. Res. 76, 108-113 (2012). 
26. Delroisse, J., Bonneel, M., Demeuldre, M., Eeckhaut, I. \& Flammang, P. Integument transcriptome profile of the European sea cucumber Holothuria forskali. Preprint at https://www.biorxiv.org/content/10.1101/2021.02.12.430961v1 (2021).

27. Montagnani, C., Le Roux, F., Berthe, F. \& Escoubas, J.M. Cg-TIMP, an inducible tissue inhibitor of metalloproteinase from the Pacific oyster Crassostrea gigas with a potential role in wound healing and defense mechanisms. FEBS Lett. 500, 64-70 (2001).

28. Clouse, R.M., Linchangco, G.V., Kerr, A.M., Reid, R.W. \& Janies, D.A. Phylotranscriptomic analysis uncovers a wealth of tissue inhibitor of metalloproteinases variants in echinoderms. R. Soc. Open. Sci. 2, 150377 (2015).

29. Patel, S.S., Belmont, B.J., Sante, J.M. \& Rexach, M.F. Natively unfolded nucleoporins gate protein diffusion across the nuclear pore complex. Cell 129, 83-96 (2007).

30. Ahern, C.A., Eastwood, A.L., Lester, H.A., Dougherty, D.A. \& Horn, R. A cation- $\pi$ interaction between extracellular TEA and an aromatic residue in potassium channels. J. Gen. Physiol. 128, 649-657 (2006).

31. Cardin, A.D. \& Weintraub, H.J. Molecular modelling of protein-glycosaminoglycan interactions. Arteriosclerosis 9, 21-32 (1989).

32. Hileman, R.E., Fromm, J.R., Weiler, J.M. \& Linhardt, R.J. Glycosaminoglycan-protein interactions: definition of consensus sites in glycosaminoglycan binding proteins. BioEssays 20, 156-167 (1998).

33. Brew, K. \& Nagase, H. The tissue inhibitors of metalloproteinases (TIMPs): an ancient family with structural and functional diversity. Biochim. Biophys. Acta 1803, 55-71 (2010).

34. Wilkie, I.C., Fassini, D., Cullorà, E., Barbaglio, A., Tricarico, S., Sugni, M., Del Giacco, L. \& Candia Carnevali, M.D. Mechanical properties of the compass depressors of the sea-urchin Paracentrotus lividus (Echinodermata, Echinoidea) and the effects of enzymes, neurotransmitters and synthetic tensilin-like protein. PLoS One 10, e0120339 (2015).

35. Ribeiro, A.R., Barbaglio, A., Oliveira, M.J., Ribeiro, C.C., Wilkie, I.C., Candia Carnevali, M.D. \& Barbosa, M.A. Matrix metalloproteinases in a sea urchin ligament with adaptable mechanical properties. PLoS One 7, e49016 (2012).

36. Dolmatov, I.Y., Afanasyev, S.V. \& Boyko, A.V. Molecular mechanisms of fission in echinoderms: Transcriptome analysis. PLoS One 13, e0195836 (2018).

37. Bányai, L. \& Patthy, L. The NTR module: domains of netrins, secreted frizzled related proteins, and type I procollagen C-proteinase enhancer protein are homologous with tissue inhibitors of metalloproteases. Prot. Sci. 8, 1636-1642 (1999).

38. Weiss, T., Brusel, M., Rousselle, P. \& Kessler, E. The NTR domain of procollagen Cproteinase enhancer-1 (PCPE-1) mediates PCPE-1 binding to syndecans-1, -2 and -4 as well as fibronectin. Int. J. Biochem. Cell Biol. 57, 45-53 (2014).

39. Moschcovich, L., Bernocco, S., Font, B., Rivkin, H., Eichenberger, D., Chejanovsky, N., Hulmes, D.J.S. \& Kessler, E. Folding and activity of recombinant human procollagen Cproteinase enhancer. Eur. J. Biochem. 268, 2991-2996 (2001). 
40. Weiss, T., Ricard-Blum, S., Moschcovich, L., Wineman, E., Mesilaty, S. \& Kessler, E. Binding of procollagen C-proteinase enhancer-1 (PCPE-1) to heparin/heparan sulfate: properties and role in PCPE-1 interaction with cells. J. Biol. Chem. 285, 33867-33874 (2010).

41. Yu, W.-H. \& Woessner, J.F. Heparan sulfate proteoglycans as extracellular docking molecules for matrilysin (Matrix Metalloproteinase 7). J. Biol. Chem. 275, 4183-4191 (2000).

42. Haas, B.J., Papanicolaou, A., Yassour, M., Grabherr, M., Blood, P.D., Bowden, J., Couger, M.B., Eccles, D., Li, B., Lieber, M., MacManes, M.D., Ott, M., Orvis, J., Pochet, N., Strozzi, F., Weeks, N., Westerman, R., William, T., Dewey, C.N., Henschel, R., LeDuc, R.D., Friedman, N. \& Regev, A. De novo transcript sequence reconstruction from RNA-seq using the Trinity platform for reference generation and analysis. Nat. Protoc. 8, 1494-1512 (2013).

43. Gasteiger, E., Gattiker, A., Hoogland, C., Ivanyi, I., Appel, R.D. \& Bairoch, A. ExPASy: The proteomics server for in-depth protein knowledge and analysis. Nucleic Acids Res. 31, 3784-3788 (2003).

44. Frickey, T. \& Lupas, A. CLANS: a Java application for visualizing protein families based on pairwise similarity. Bioinformatics 20, 3702-3704 (2004).

45. Janies, D.A., Witter, Z., Linchangco, G.V., Foltz, D.W., Miller, A.K., Kerr, A.M., Jay, J., Reid, R.W. \& Wray, G.A. EchinoDB, an application for comparative transcriptomics of deeplysampled clades of echinoderms. BMC Bioinformatics 17, 48 (2016).

46. Katoh, K. \& Standley, D.M. MAFFT multiple sequence alignment software version 7: improvements in performance and usability. Mol. Biol. Evol. 30, 772-780 (2013).

47. http://imed.med.ucm.es/Tools/sias.html

48. Capella-Gutiérrez, S., Silla-Martínez, J.M. \& Gabaldón, T. trimAl: a tool for automated alignment trimming in large-scale phylogenetic analyses. Bioinformatics 25, 1972-1973 (2009).

49. Helaers, R. \& Milinkovitch, M.C. MetaPIGA v2.0: maximum likelihood large phylogeny estimation using the metapopulation genetic algorithm and other stochastic heuristics. BMC Bioinformatics 11, 379 (2010).

50. Guindon, S., Dufayard, J. F., Lefort, V., Anisimova, M., Hordijk, W. \& Gascuel, O. New algorithms and methods to estimate maximum-likelihood phylogenies: assessing the performance of PhyML 3.0. Syst. Biol. 59, 307-321 (2010).

51. Lefort, V., Longueville, J. E. \& Gascuel, O. SMS: Smart Model Selection in PhyML. Mol. Biol. Evol. 34, 2422-2424 (2017).

52. Rambaut, A. FigTree 1.4.2 software. Institute of Evolutionary Biology, University of Edinburgh (2014).

53. Lu, S., Wang, J., Chitsaz, F., Derbyshire, M.K., Geer, R.C., Gonzales, N.R., Gwadz, M., Hurwitz, D.I., Marchler, G.H., Song, J.S., Thanki, N., Yamashita, R.A., Yang, M., Zhang, D., Zheng, C., Lanczycki, C.J. \& Marchler-Bauer, A. CDD/SPARCLE: the conserved domain database in 2020. Nucleic Acids Res. 48, D265-D268 (2020). 
54. Almagro Armenteros, J.J., Tsirigos, K.D., Sønderby, C.K., Petersen, T.N., Winther, O., Brunak, S., von Heijne, G. \& Nielsen, H. SignalP 5.0 improves signal peptide predictions using deep neural networks. Nat. Biotechnol. 37, 420-423 (2019).

55. Waterhouse, A., Bertoni, M., Bienert, S., Studer, G., Tauriello, G., Gumienny, R., Heer, F.T., de Beer, T.A.P., Rempfer, C., Bordoli, L., Lepore, R. \& Schwede, T. SWISS-MODEL: homology modelling of protein structures and complexes. Nucleic Acids Res., 46, W296-W303 (2018).

56. Trotter, J.A., Lyons-Levy, G., Luna, D., Koob, T.J., Keene, D.R. \& Atkinson, M.A. Stiparin: a glycoprotein from sea cucumber dermis that aggregates collagen fibrils. Matrix Biol. 15, 99-110 (1996).

57. Wu, Z.L., Prather, B., Ethen, C.M., Kalyuzhny, A. \& Jiang, W. Detection of specific glycosaminoglycans and glycan epitopes by in vitro sulfation using recombinant sulfotransferases. Glycobiology 21, 625-633 (2011).

58. Santos, R., Haesaerts, D., Jangoux, M. \& Flammang, P. The tube feet of sea urchins and sea stars contain functionally different mutable collagenous tissues. J. Exp. Biol. 208, 2277-2288 (2005).

59. Hennebert, E., Haesaerts, D., Dubois, P. \& Flammang, P. Evaluation of the different forces brought into play during tube foot activities in sea stars. J. Exp. Biol. 213, 1162-1174 (2010).

\section{Acknowledgments}

The authors thank Nathan Puozzo who designed the schematic model in Fig. 8. The bioprofiling platform used for the de novo peptide sequencing analysis was supported by the European Regional Development Fund and the Walloon Region. J.D. and P.F. are, respectively, Postdoctoral Researcher and Research Director of the F.R.S.-FNRS. This study is a contribution of the Centre Interuniversitaire de Biologie Marine.

\section{Funding:}

This work was supported by the Fund for Scientific Research of Belgium (F.R.S.-FNRS) FRIA doctoral grant 17953 (M.B.); the Fund for Medical Research in Hainaut (F.R.M.H.) (E.H.); the Academy of Finland projects 308772, 333238 (A.S.A.); the Academy of Finland's Center of Excellence programme 20142019 (A.S.A.); the Fédération Wallonie-Bruxelles - Actions de Recherche Concertées ARC project "PROTEST", ARC-17/21 UMONS 3 (E.H., R.W., P.F.); and the Fund for Scientific Research of Belgium (F.R.S.-FNRS) "Projet de Recherche" T.0088.20 (P.F.)

Author contributions: M.B., E.H. and P.F. designed research; M.B., E.H., M.L., V.P., J.D., R.W. and P.F. performed experiments; M.B., E.H., A.S.A., J.D., D.S.H. and P.F. analysed data; M.B., E.H., J.D. and P.F wrote the first draft of the paper. All co-authors participated to discussions and revised the final manuscript.

Competing interests: Authors declare that they have no competing interests. 
Data and materials availability: All data are available in the main text or the supplementary materials. 


\section{Figures and Tables}
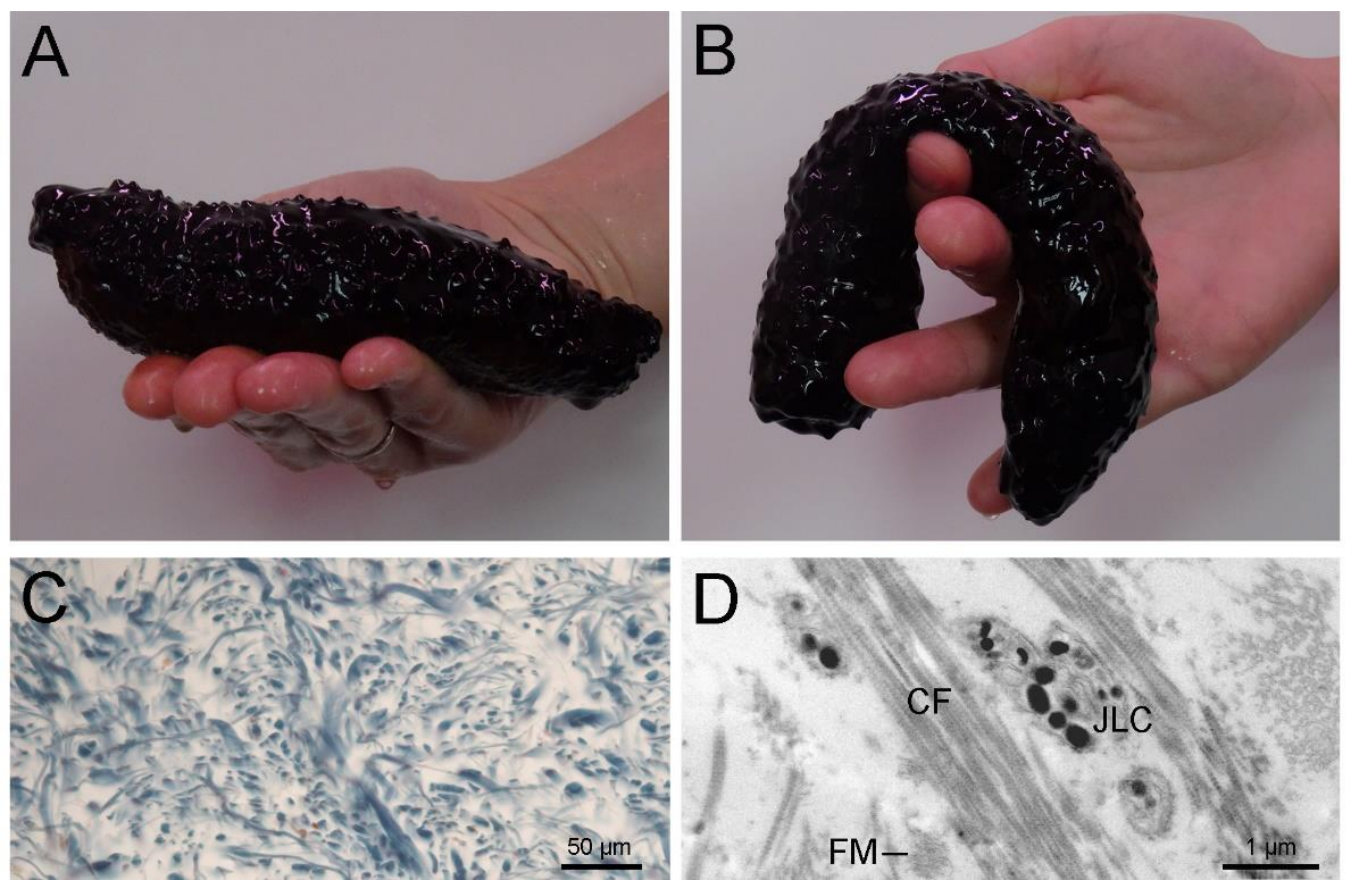

Fig. 1. The dermis of Holothuria forskali is a mutable collagenous tissue (MCT). (A) Sea cucumber in the stiff state after mechanical stimulation and (B) in the soft state. (C) Transverse section through the dermis stained with Heidenhain's Azan showing collagen fibres in blue. (D) TEM view of the dermis showing bundles of collagen fibrils (CF) interspersed with fibrillin microfibrils (FM) and juxtaligamental-like cells (JLC). 

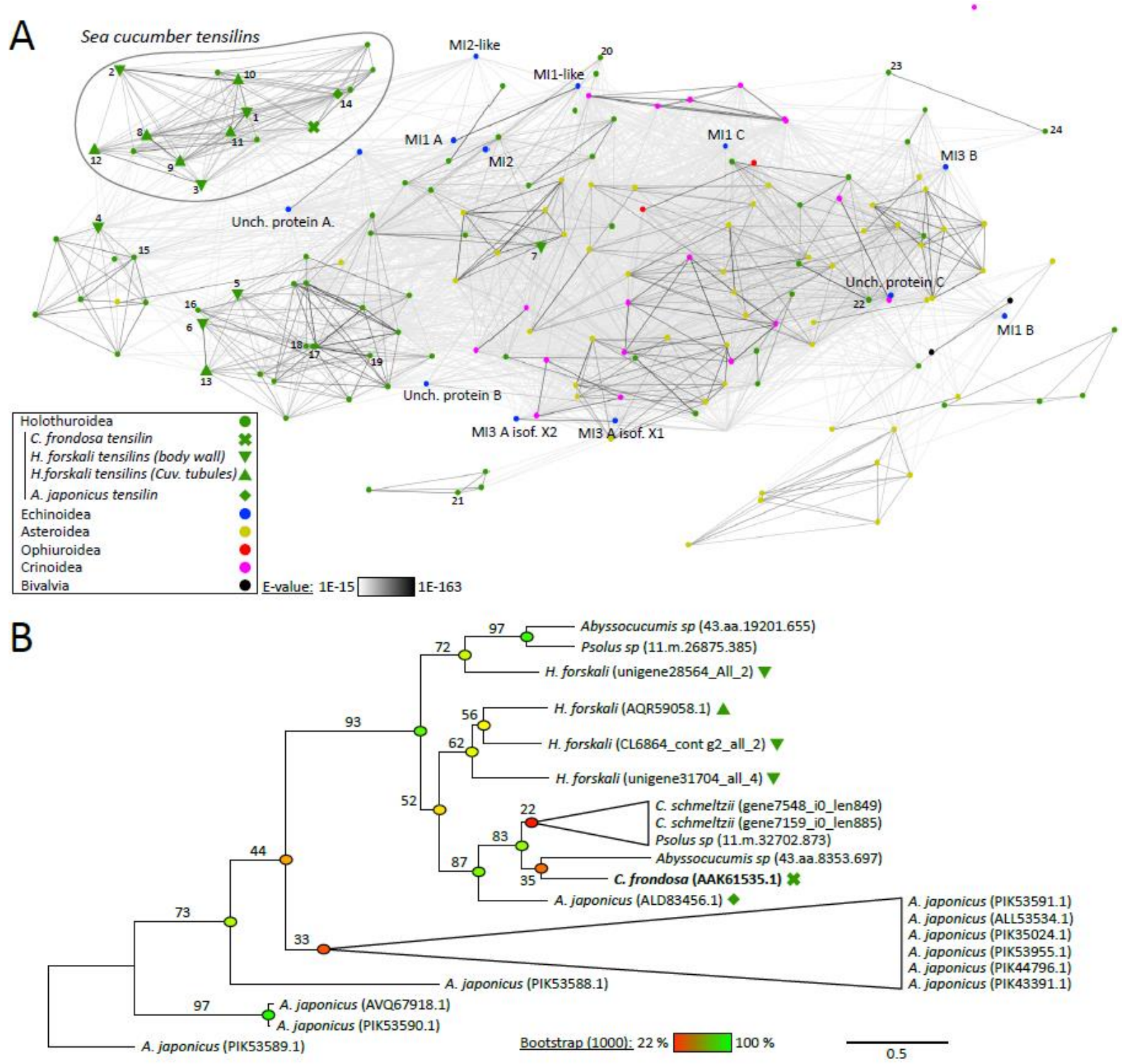

Fig. 2. Similarity of tensilin candidates from the body wall of Holothuria forskali with other echinoderm TIMP-like sequences. (A) Sequence-similarity-based clustering approach based on BLASTp e-values (CLANS software) with tensilins from $C$. frondosa, A. japonicus and $H$. forskali and closely related homologous echinoderm sequences. The names and accession numbers of the sequences corresponding to the numbers from 1 to 24 in the figure are referenced in the Table S1. The sea urchin sequence names (blue circles) are annotated on the figure and refer to the genome of Strongylocentrotus purpuratus. These sequences are annotated as metalloproteinase inhibitor, initially known as TIMP-like proteins. The full names of these sequences can be found in the Table S1. (B) Maximum-likelihood phylogenetic tree of the sea cucumber tensilin sequences subset selected from the CLANS clustering analysis and circled in (A). The published tensilin sequence for the Cuvierian tubules of $\mathrm{H}$. forskali (AQR59058) was the only Cuvierian tubule sequence used in the analysis. Three other candidates (encoded by transcripts comp8229, comp80300 and comp71415) were not selected on the final tree as they were grouped with body wall candidates (encoded by transcripts unigene28564, CL6864 and unigene31704, respectively) with bootstrap values of 100 . 


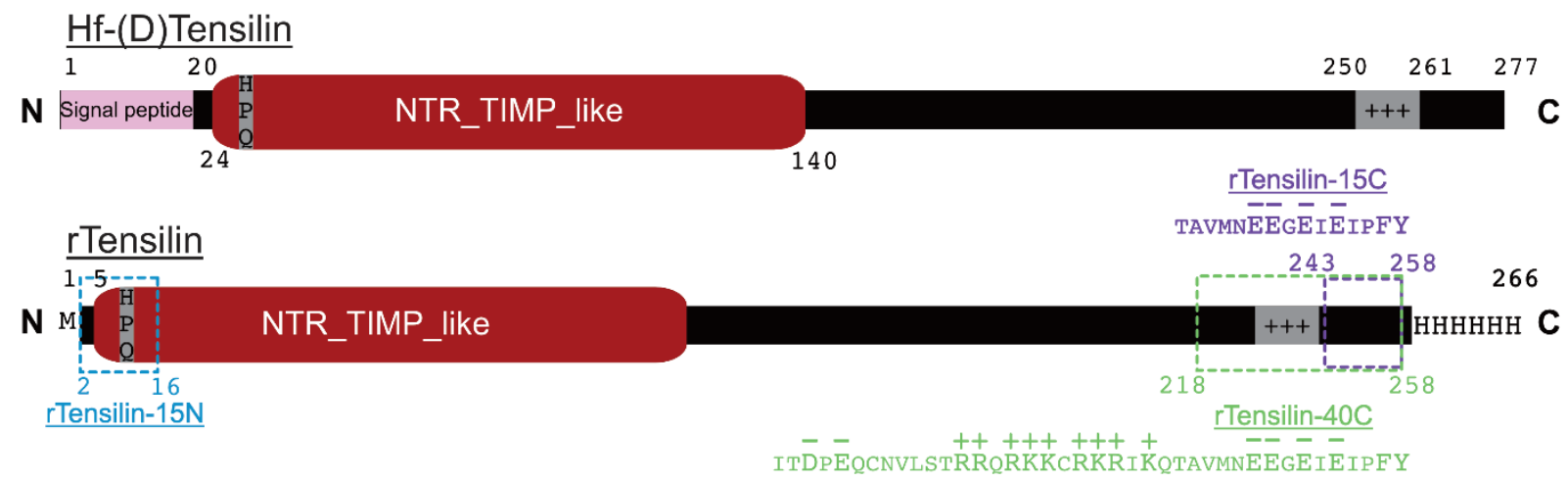

Fig. 3. Schematic view of native and recombinant Hf-(D)Tensilin. Red: NTR_TIMP_like domain predicted by the Conserved Domain Database. The signal peptide of the native protein is highlighted in pink. The HPQ sequence, characteristic of TIMPs, and the positive charge cluster, characteristic of tensilins, are highlighted in grey. The first 15 amino acids removed from the $\mathrm{N}$-terminal part and the 15 and 40 last amino acids removed from the $\mathrm{C}$-terminal part for the production of truncated recombinant proteins are highlighted in blue (rTensilin-15N), purple (rTensilin-15C) and green (rTensilin-40C). The positively charged, negatively charged, and aromatic amino acids are highlighted in the C-terminal part of the recombinant protein. 

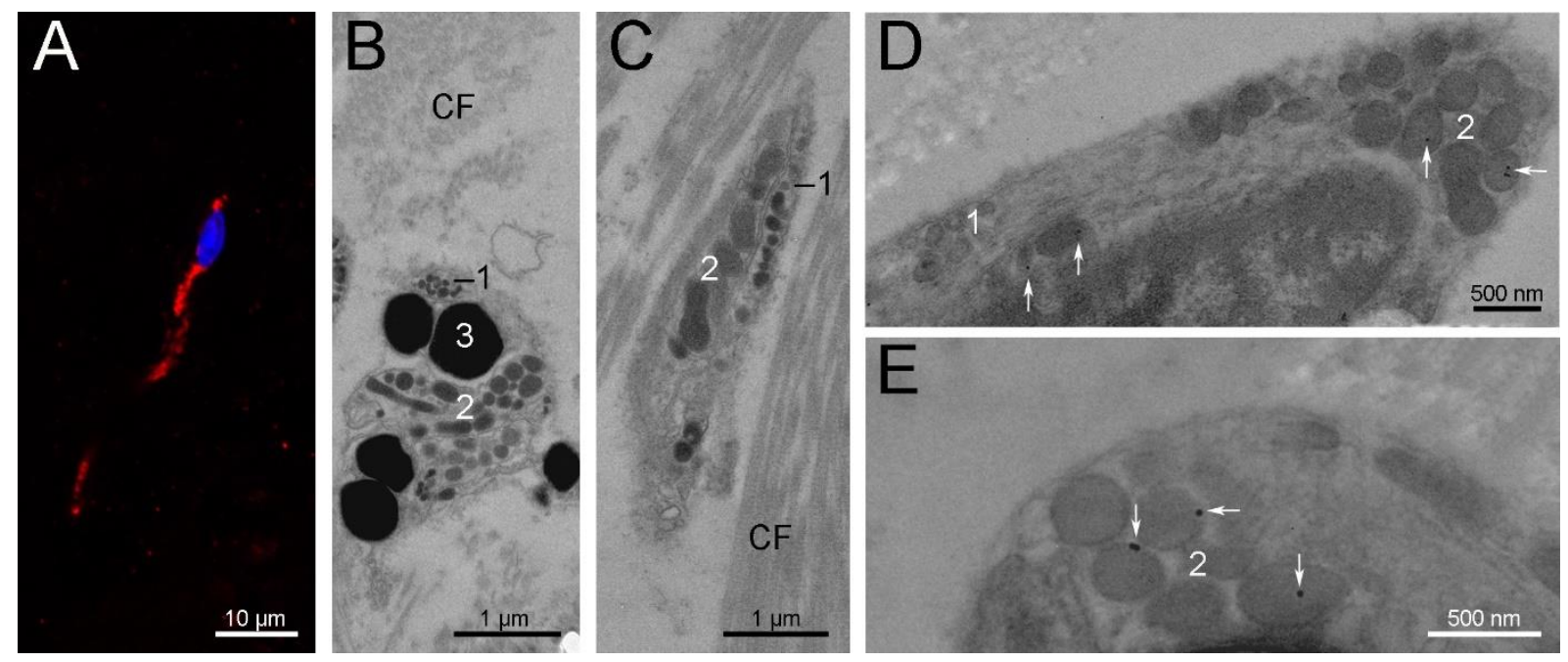

Fig. 4. Hf-(D)Tensilin localization on longitudinal sections through the dermis of H. forskali. (A) Immunofluorescence with antibodies directed against the peptide NPHKSREFSEIEDC (red). Stack of 5 images taken in layers on the same spot of the dermis section. See Fig. S3 for separate images. Blue: DAPI staining of the nucleus. (B,C) TEM photographs showing the three types of juxtaligamental-like cells (JLC) and bundles of collagen fibrils (CF) in the dermis. 1: type 1 JLCs containing small granules; 2: type 1 JLCs containing medium-size granules; and 3: type 3 JLCs containing large granules. (D,E) Immunocytochemical localization of Hf-(D)Tensilin in the granules of type $2 \mathrm{JLCs}$, but not of type 1 JLCs (arrows indicate the immunogold labelling with antibodies directed against the peptide NPHKSREFSEIEDC). 

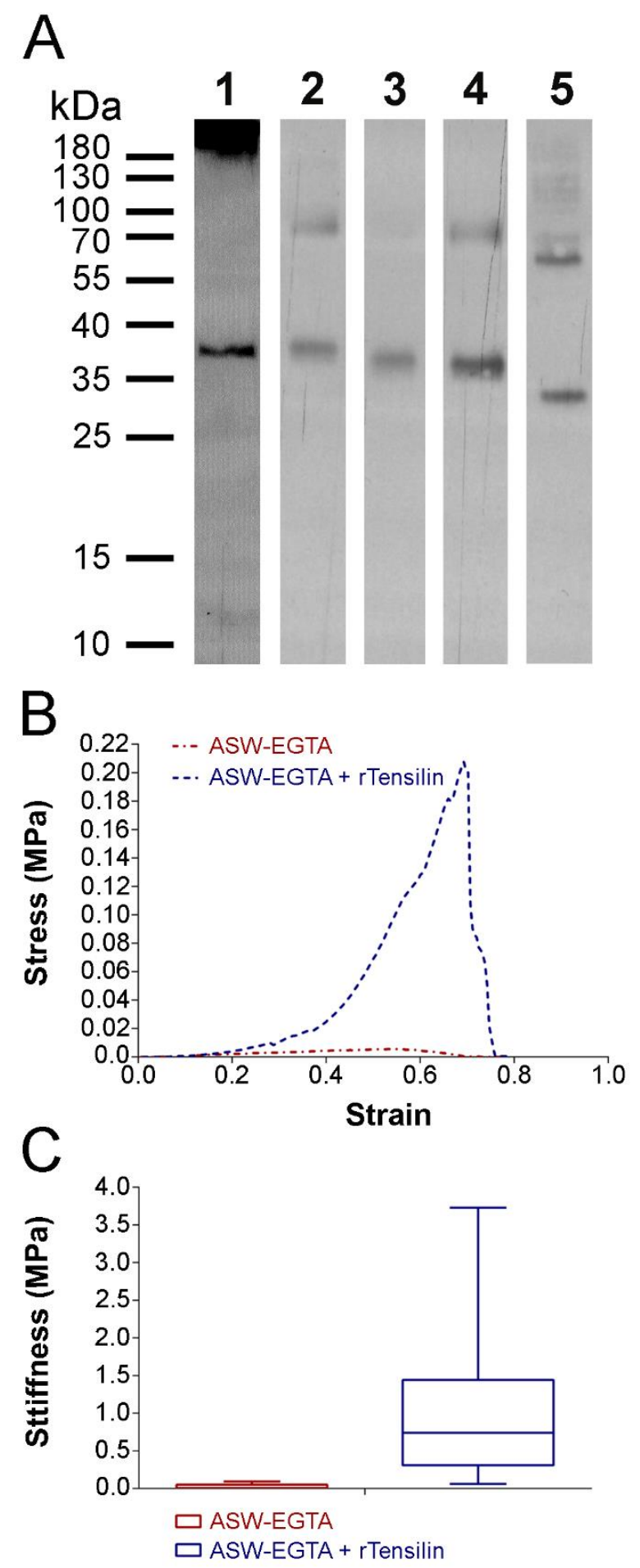

Fig. 5. Recombinant Hf-(D)Tensilin production and characterization. (A) Confirmation of the identity of the proteins by Western blot. Proteins extracted from the dermis of $H$. forskali (1) and eluted fraction of recombinant tensilins after production in E. coli, purification, and dialysis (2: rTensilin, 3: rTensilin-15N, 4: rTensilin-15C, 5: rTensilin-40C) were separated by SDS-PAGE on a $12 \%$ gel and analyzed by Western blot using anti- NPHKSREFSEIEDC polyclonal antibodies. (B,C) Influence of rTensilin on the mechanical properties of the dermis. Representative stress-strain curves of pieces of dermis of $H$. forskali incubated in $1.3 \mathrm{ml}$ of ASW-EGTA supplemented or not with $12.5 \mu \mathrm{g} / \mathrm{ml} \mathrm{rTensilin}$ (B), and boxplots for dermis stiffness calculated from these curves ( $n=6$ pieces) (C). 

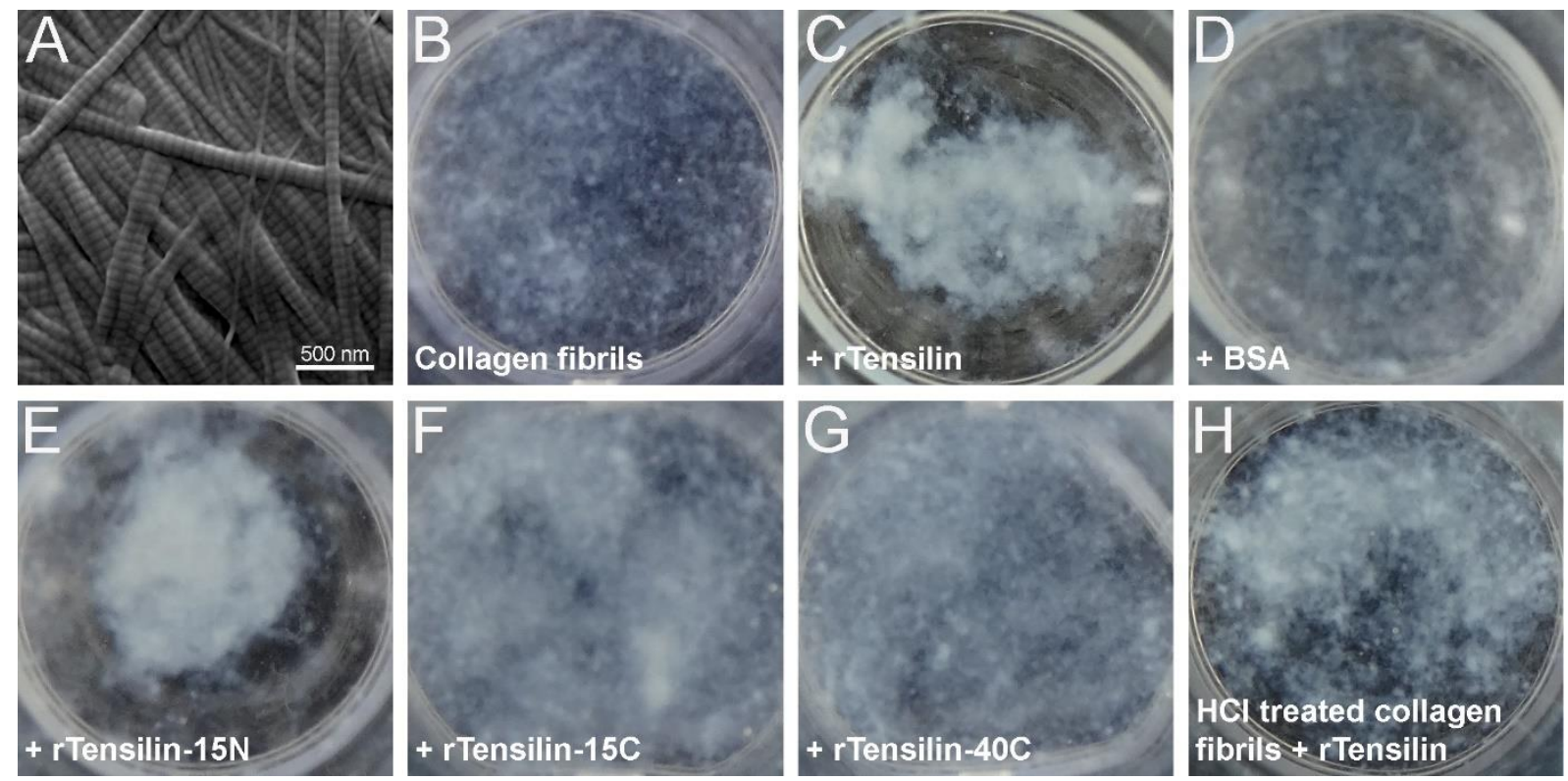

Fig. 6. Dermis collagen fibrils and aggregation assays. (A) SEM photograph of collagen fibrils extracted from the dermis of $H$. forskali. (B-G) Collagen fibrils in $20 \mathrm{mM}$ Tris- $\mathrm{HCl}, 0.5 \mathrm{M} \mathrm{NaCl}, 2 \mathrm{mM}$ EGTA, pH 8.0 (buffer 2) without (B) or with addition of $55 \mu \mathrm{g} / \mathrm{ml}$ of rTensilin (C), BSA (D), rTensilin$15 \mathrm{~N}(\mathbf{E})$, rTensilin-15C (F) or rTensilin-40C (G). (H) collagen fibrils after $\mathrm{HCl}$ treatment mixed with $55 \mu \mathrm{g} / \mathrm{ml}$ of rTensilin. 


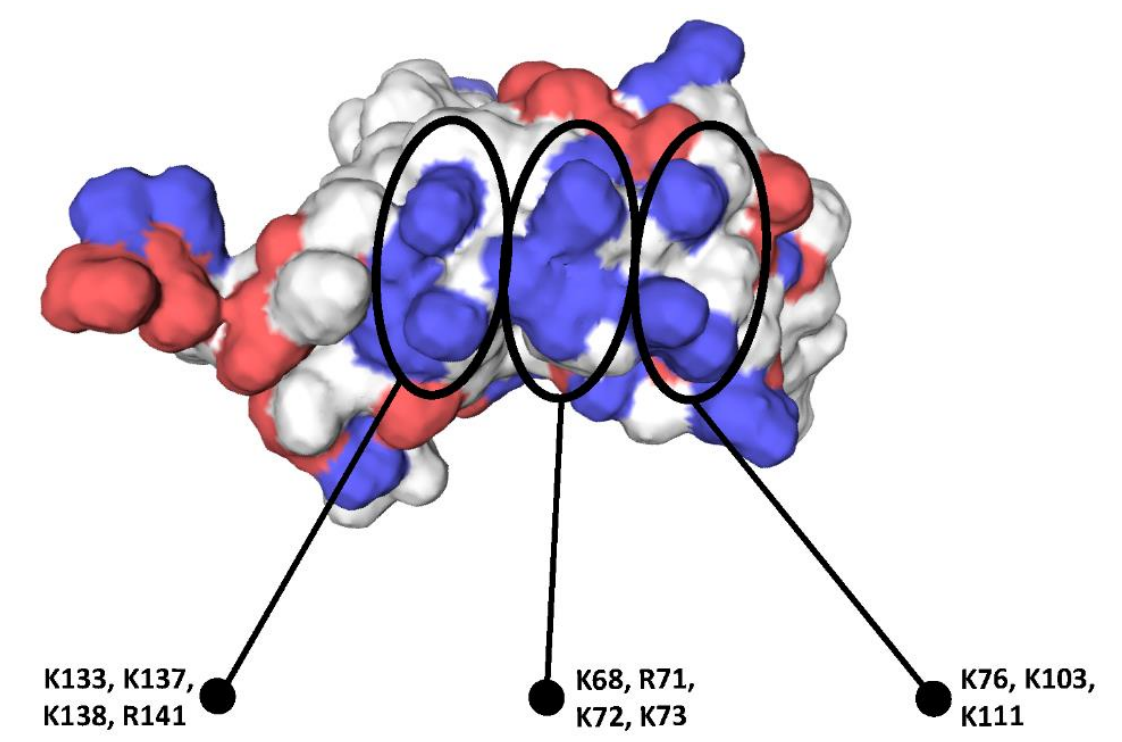

A. japonicus (ALD83456.1)

H. forskali (AQR59058.1)
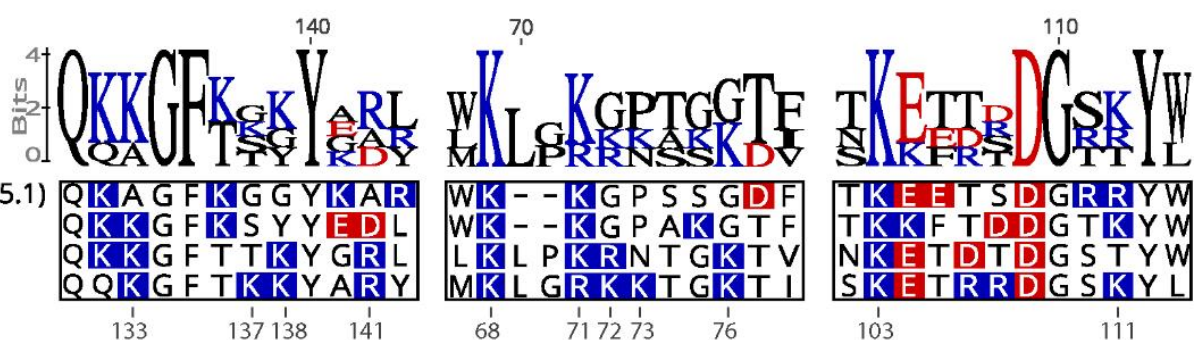

L KL PKRNTGKT V

MKL GR K KT GKT I

68

$\underbrace{717273 \quad 76}$

TIKEET SIDGRRYW

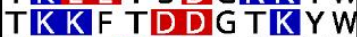

NKE TDTDG S TYW

STETRRDG SKY L

103

111

Fig. 7. Surface charge on the NTR domain of Hf-(D)Tensilin. The positive charges are shown in blue and negative charges in red. An area of clustered positive charges was found on the surface of Hf(D)Tensilin, consisting of three patches formed by residues K133, K137, K138 and R141; K68, R71, K72 and K73; and K76, K103 and K111; respectively. The lower part of the figure shows a sequence alignment of tensilins from different species, limited to the three regions corresponding to the patches. The basic amino acids are highlighted in blue and the acidic in red. The bracket indicates the putative GAG-binding sequence GRKKTGKT (residues 70-77). Although these regions are not highly conserved, they always comprise several basic residues at similar positions. 


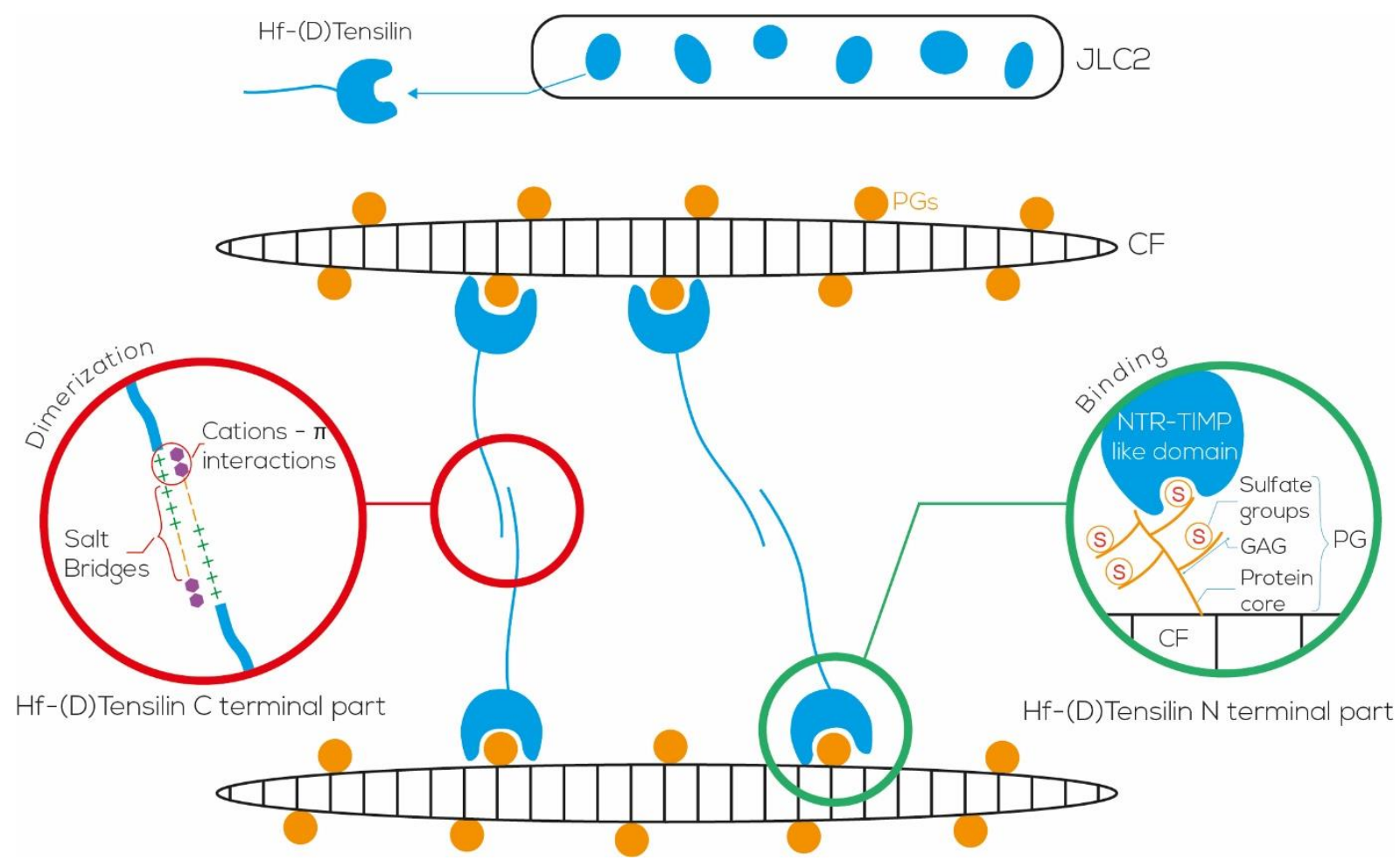

Fig. 8. Model of molecular interactions between tensilin and collagen fibrils within the sea cucumber body wall dermis. Hf-(D)Tensilin is released from the granules of type 2 juxtaligamentallike cells (JLC2). Two types of interactions allow the cross-linking of collagen fibrils (CF): (1) Dimerization or oligomerization of tensilin molecules via positively and negatively charged amino-acids acids interactions and cation- $\pi$ interactions at the C-terminal part of tensilin (red circles). And (2) binding of the NTR-TIMP like domain at the N-terminal part of tensilin with the sulfates from the proteoglycans (PGs) at collagen fibrils surface (green circles). 
Table 1. Similarity matrix (SIAS web tool) comparison of tensilin-like protein sequences translated from transcripts expressed in the body wall of $H$. forskali with published tensilins from A. japonicus, from the dermis (D) of $C$. frondosa, and from the Cuvierian tubules (CT) of $H$. forskali. Only the proteins encoded by the three transcripts in bold belong to the "Sea cucumber tensilins" cluster of the CLANS analysis (Fig. 2A).

\begin{tabular}{|c|c|c|c|}
\hline & $\begin{array}{l}\text { A. japonicus } \\
\text { ALD83456 }\end{array}$ & $\begin{array}{l}\text { C. frondosa (D) } \\
\text { AAK61535 }\end{array}$ & $\begin{array}{l}\text { H. forskali }(\mathrm{CT}) \\
\text { AQR59058 }\end{array}$ \\
\hline CL6864 (Hf-(D)Tensilin) (FPKM: 49,079) & $65.63 \%$ & $59.21 \%$ & $74.44 \%$ \\
\hline Unigene31704 $\quad$ (FPKM: 22,944) & $61.13 \%$ & $56.47 \%$ & $66.32 \%$ \\
\hline$($ FPKM : 29,751) & $53.8 \%$ & $51.26 \%$ & $58.37 \%$ \\
\hline (FPKM : 183,419) & $38.35 \%$ & $42 \%$ & $43.83 \%$ \\
\hline (FPKM : 976,242) & $40.27 \%$ & $42.59 \%$ & $43.51 \%$ \\
\hline$(\mathrm{FPKM}: 175,124$ & $43.17 \%$ & $41.04 \%$ & $46.25 \%$ \\
\hline (FPKM : 332,594) & $38.05 \%$ & $40.7 \%$ & $41.59 \%$ \\
\hline
\end{tabular}


Table 2. Effect of different test molecules on rTensilin-induced collagen fibril aggregation and on the binding of rTensilin to collagen fibrils.

\begin{tabular}{|c|c|c|c|}
\hline Test solution & $\begin{array}{l}\text { Aggregate } \\
\text { inhibition }^{\text {a }}\end{array}$ & $\begin{array}{l}\text { Aggregate } \\
\text { destabilization }^{b}\end{array}$ & $\begin{array}{l}\text { rTensilin } \\
\text { binding } \\
\text { collagen }^{c}\end{array}$ \\
\hline Heparin $4 \%$ & + & + & - \\
\hline Arg $17 \mathrm{mM}$ & + & + & + \\
\hline Lys $17 \mathrm{mM}$ & + & + & + \\
\hline Gly $17 \mathrm{mM}$ & - & - & ND \\
\hline Asp $17 \mathrm{mM}$ & + & + & + \\
\hline Glu $17 \mathrm{mM}$ & + & + & + \\
\hline $\mathrm{NaCl} 1.88 \mathrm{M}$ & - & - & ND \\
\hline $\mathrm{NaCl} 2.5 \mathrm{M}$ & $+/-$ & $+/-$ & + \\
\hline $\mathrm{MgCl}_{2} 0.35 \mathrm{M}$ & $+/-$ & $+/-$ & ND \\
\hline EGTA $20 \mathrm{mM}$ & - & - & ND \\
\hline EDTA $20 \mathrm{mM}$ & - & - & ND \\
\hline 1,6-hexanediol $0.21 \mathrm{M}$ & $+/-$ & $+/-$ & + \\
\hline TEA $0.15 \mathrm{M}$ & $+/-$ & $+/-$ & + \\
\hline $\begin{array}{l}\text { Peptide DGMKLGRKKTGKTI } \\
25 \mu \mathrm{M}\end{array}$ & - & - & + \\
\hline $\begin{array}{l}\text { Peptide NPHKSREFSEIEDC } \\
25 \mu \mathrm{M}\end{array}$ & - & - & + \\
\hline
\end{tabular}

ND not determined

${ }^{a}$ Collagen fibrils were pre-mixed with the test molecules before addition of rTensilin. (+) strong inhibitory effect, (-) no inhibitory effect, (+/-) slower or incomplete inhibitory effect.

b Aggregates obtained with rTensilin beforehand were mixed with the test molecules. $(+)$ strong destabilization effect, (-) no destabilization effect, (+/-) slower or incomplete destabilization effect.

${ }^{\mathrm{c}}$ Binding of rTensilin to collagen fibrils was assessed by centrifugating collagen fibrils after aggregation tests, submitting them to extraction in SDS sample buffer, and visualizing the presence $(+)$ or absence $(-)$ of the band corresponding to rTensilin after SDS-PAGE. 


\section{Supplementary Files}

This is a list of supplementary files associated with this preprint. Click to download.

- SuppIDataBonneelTensilin.xIsx

- BonneelTensilinSupplementaryMaterials.pdf 